\title{
Alcohol use, its predictors and academic performance among Malaysian students of a medical college in India
}

\author{
Vasudha Devi ${ }^{1}$, Alicia Tan Wei Ping ${ }^{2}$, Tan Tuan Ying ${ }^{2}$, Sadhin Subhash ${ }^{2}$, Samia Mahmood \\ Hafez Amir ${ }^{2}$ \\ ${ }^{1}$ Pharmacology, ${ }^{2}$ Students, Melaka Manipal Medical College, Manipal Campus, Manipal University, India
}

\begin{tabular}{ll}
\hline ARTICLE INFO \\
Received & $: 15 / 02 / 2013$ \\
Accepted & $: 15 / 05 / 2013$ \\
Published & $: 01 / 12 / 2013$
\end{tabular}

\section{KEYWORD}

Alcohol consumption Academic performance Medical students

\begin{abstract}
Several studies reveal high rates of alcohol use among college students affecting their health and performances. This cross-sectional survey was done to study medical students' drinking pattern, its predictors and to develop any possible link between their academic performance and alcohol consumption. Data was collected using newly designed, validated questionnaire from students $(n=348)$ who consumed and not consumed alcohol. The response rate was 60\% (209/348). 94\% of drinkers started consuming alcohol before entering into the medical school. Most of them (85\%) drank with parents' awareness. Among drinkers, 63\% were of Chinese race and $35 \%$ of Indian race. None of the Malay respondents reported of drinking. $63 \%$ of drinkers and $23 \%$ of non-drinkers reported that most of their friends consumed alcohol. Drinking was not associated with smoking or drug abuse. There were no statistically significant differences in exam scores between drinkers and nondrinkers. Non-drinkers considered religious and moral obligations for not consuming alcohol. In conclusion, at our Institute, students did not allow their alcohol use to interfere with their academic performance. The drinking habit developed during school time is more likely to continue during college years. Those who have non-drinking friends are more likely not to consume alcohol themselves. Moral and religious obligations have positive impact on alcohol intake.
\end{abstract}

(C) Medical Education Department, School of Medical Sciences, Universiti Sains Malaysia. All rights reserved.

CORRESPONDING AUTHOR: Vasudha Devi, Professor and Head Department of Pharmacology, Melaka Manipal Medical College, Manipal University, Manipal, India 576104. Email: v21devi@gmail.com

\section{Introduction}

Epidemiological findings on adolescent and young adult alcohol use, reveal high rates of alcohol use among these age groups. Drinking practices in this age group was associated with youth mortality and with disruptions in significant contexts (e.g., school, work, family) that are important for healthy development [1]. The same study not only demonstrated the common co-occurrence of tobacco use, illicit drug use, risky sexual behavior among heavier users but also distinct drinking subcultures on many college campuses that foster negative consequences for both drinkers and those around them. These findings force colleges to shoulder responsibilities that support the educational environment that is conducive to learning.

Previous studies suggest that the magnitude of the association between undergraduate alcohol use and academic performance is small [2]. 
However, conclusions drawn in recent fewer studies like, a general acceptance among undergraduate medical students that alcohol could provide positive reinforcement [3] and alcohol intake is considered as one of the method to deal with stress among medical students $[4,5]$ have made it important to look into the problem in each educational setting.

Majority of the students admitted to our Institute are Malaysians belonging to 3 major ethnic groups, Malays, Chinese and Indians. These students study medicine in two campuses. After completing first two and half a year of Bachelor of Medicine and Bachelor of Surgery (MBBS) course, students proceed to Malaysia for clinical training. A study done in Selangor, Malaysia, showed that alcohol use is prevalent among students of primary ( 7 to 12 years of age) and secondary levels ( 13 to 20 years of age) [6], possibly affecting their performance in life. After completing secondary level students enter University. As our students are Malaysians, the current study was designed to study their drinking behavior and to develop any possible link between their academic performance and alcohol consumption.

\section{Method}

\section{Study Design}

This cross sectional study was done on medical students of $1^{\text {st }}(n=148)$ and $2^{\text {nd }}$ years $(n=200)$ of the course in December 2012.

\section{Data Collection}

A newly developed self-administered questionnaire was used for data collection. The items in the questionnaire were selected after literature review $[1,2,6,7]$. The questionnaire had 18 items. As the study required the academic performance of drinkers and nondrinkers, the questionnaire designed had items to gather required data from both the groups. To compare academic performance of the groups, we gathered performance grades based on the marks obtained in formative assessments $(\mathrm{C}=\leq 50 \%$, $\mathrm{B}=50 \%-74 \%, \mathrm{~A}=\geq 75 \%$ ).
The questionnaire so constructed was reviewed by two faculty members to see if the items were appropriate to capture the issue concerned. Later, the questionnaire was pilot tested by 5 students and the necessary modifications were made based on feedback obtained during pilot testing.

Students responded in the questionnaire in their lecture class rooms after giving informed consent. The data obtained was anonymous.

\section{Analysis}

Data was expressed in percentages. Analysis was done using SPSS version 16. The comparison of academic performance of drinkers and nondrinkers was done using Chi-square test. A $\mathrm{p}$ value of $<0.05$ was considered as statistically significant.

\section{Result}

The response rate was $60 \%(209 / 348)$. Table 1 shows demographic and other data of respondents.

Table 1: Demographic features and other characteristics of respondents $(\mathrm{N}=209)$

\begin{tabular}{|c|c|c|}
\hline Variable & $\begin{array}{r}\text { Nondrinker, } \\
\%\end{array}$ & $\begin{array}{r}\text { Drinker, } \\
\%\end{array}$ \\
\hline Overall & 70 & 30 \\
\hline \multicolumn{3}{|l|}{ Sex } \\
\hline Males & 65.9 & 53.7 \\
\hline Females & 34.1 & 46.3 \\
\hline \multicolumn{3}{|l|}{ Race } \\
\hline Chinese & 29.4 & 62.9 \\
\hline Indians & 18.3 & 35.2 \\
\hline Malays & 54.2 & 0 \\
\hline Others & 7.1 & 1.9 \\
\hline \multicolumn{3}{|l|}{$\begin{array}{l}\text { Regularity in study } \\
\text { practices }\end{array}$} \\
\hline Regular & 77 & 52 \\
\hline During weekends & 10 & 4 \\
\hline Only for the exams & 13 & 20 \\
\hline No response & - & 24 \\
\hline \multicolumn{3}{|l|}{ Friends drinking alcohol } \\
\hline Most of them & 23 & 63 \\
\hline Few of them & 53 & 19 \\
\hline None of them & 20 & 0 \\
\hline
\end{tabular}

The commonly used alcohol beverage was beer (40\%), followed by wine (32\%), mixed drinks and malt beverages. $94 \%$ of drinkers started 
consuming alcohol before entering into the medical school i.e. before the age of 20. Only $6 \%$ of them started the habit after joining the medical school. Majority of the drinkers (85\%) consumed with parents' consent and 95\% of the drinkers were aware of the health and social consequences of alcoholism.

Drinkers attributed reasons for consuming alcohol as the way of socializing (40\%), followed by as a way to deal with stress (20\%). It was surprising to note that $27 \%$ of drinkers said they did not have any particular reason for drinking and $10 \%$ drank as their friends drink. Around 20\% drinkers consumed alcohol as liked the taste and $10 \%$ consumed alcohol to get drunk. Majority (36\%) of the drinkers consumed alcohol in social gatherings (parties, weddings etc.), $28 \%$ consumed alcohol in their friends' places and other places chosen were home and restaurants.

In spite of the alcohol consumption, 94\% of the drinkers had not missed any particular important event after taking alcohol. $4 \%$ of the drinkers opined that they had missed some important events due to alcohol intake.
No difference was found related to leisure time activities among drinkers and nondrinker. Both the group preferred social networking, internet browsing, involvement in sports and extracurricular activities as leisure time activities. $10 \%$ of the drinkers also reported coexisting smoking habit. However, none of the nondrinkers were smokers. None of the subjects from both the group reported the use of other drugs of abuse.

Both the groups felt that they were reasonably attentive during lecture classes. Drinkers felt that alcohol consumption did not reduce their attentiveness during lecture classes. There were no statistically significant differences in exam scores $(p>0.05)$ between drinkers and nondrinkers (table 2).

Non-drinkers attributed religious obligations as the major reason for not consuming alcohol. Other reasons were moral obligations, health related issues, parents disapproval, no leisure time and previous bad experience with alcohol.

Table 2: Association between alcohol consumption and academic performance of students

\begin{tabular}{|c|c|c|c|c|c|}
\hline \multirow{2}{*}{$\begin{array}{l}\text { Alcohol } \\
\text { consumption }\end{array}$} & \multicolumn{3}{|c|}{ Marks obtained in \% } & \multirow{2}{*}{$X^{2}$-statistics } & \multirow{2}{*}{$P$ value } \\
\hline & $<50$ & $50-70$ & $>70$ & & \\
\hline Yes & 7 & 20 & 3 & \multirow{2}{*}{1.34} & \multirow{2}{*}{0.72} \\
\hline No & 5 & 23 & 6 & & \\
\hline
\end{tabular}

\section{Discussion}

In consistent with previous studies [2], this study did not show lower academic performance in students who consumed alcohol.

Previous studies had reported high prevalence of psychological stress [8-12] and a significant association between psychological stress and depression among medical students [8]. Studies had reported the use of alcohol and illegal drugs as a coping strategy among medical students for stress [4, 5, 13, 14]. In our study, $20 \%$ of drinkers used alcohol for coping with stress in spite of being aware of hazards of alcohol consumption. This reinforces the suggestion given by many researchers [5] regarding the need for the awareness program on substance abuse in the medical curriculum. In addition, stress coping strategies should be taught for medical students.

In our study there was no self-reported consumption of alcohol in Malay community. 
Malays are Malaysian Muslims who have religious prohibition towards alcohol consumption. Whereas, Chinese and Indian in Malaysia do not have religious prohibitions towards the consumption of alcohol. However, the underestimation of alcohol use among Muslims could be because of reluctant to express their religiously prohibited behavior as seen in other studies [6]. As reported in previous studies $[6,15]$ beer was the most common alcoholic drink taken by our students.

Earlier studies had reported the coexisting smoking and drinking habits in adolescents $[1,16]$. In our study the self-reported smoking habit was observed only in $10 \%$ of drinkers, whereas none of non-drinkers reported smoking. Though, this association is not statistically significant, the fact that, likely association between drinking and smoking habits cannot be ruled out. An earlier study done in Malaysia on 20 year old students, did not observe coexisting alcoholic and smoking habits among students [6].

In our study, majority of the students had started consuming alcohol before the age of 20, i.e. before entering into medical school. That shows, the habit of drinking began when they were in their home country. Moreover, $85 \%$ of them consumed alcohol with parents' consent/awareness and majority of their friends also consumed alcohol. The risk of alcohol consumption increases when college student experiences less parental supervision or stays in hostel and with friends [1]. However, in our study, only 6\% drinkers started consuming alcohol after joining college. Based on these finding, it can be said that, probably, the family members and friends who consumed alcohol acted as predisposing factor as seen in previous studies [7]. Hence, this study also strengthens the recommendations given by other studies that moral and religious obligations are more likely to have positive impact on alcohol intake than any other methods of policing [6,7]. In addition, educating parents on health and social hazards of alcohol intake is need of the hour.
Many studies had shown, academic stress as one of the important reason for students consuming alcohol $[7,17,18]$. Similar finding was seen in our study. Hence, in addition to educating students regarding alcoholism, creating more conducive educational environment is required to deal with the problem of alcohol consumption. Previous reports had shown that students whose friends are smokers were more likely to smoke than those whose friends are nonsmokers [19]. In our study, a similar finding was observed with alcohol intake with $63 \%$ of drinkers' friends consuming alcohol compared to only $23 \%$ of nondrinkers' friends consuming alcohol.

This study has some limitations. This was a cross sectional survey. The study showed majority of respondents did not consume alcohol. However, unwillingness of students who consume alcohol in responding to the questionnaire cannot be ruled out. Similarly, there could be underreporting of other health risk behaviors like smoking and drug use. This study has not explored the other health risk behaviors like drinking and driving, suicide, promiscuity, etc. As students perceived alcohol as one of the way to de-stress, the causes of stress among students and ways to minimize them must be explored. A prospective study to find out the changing pattern of alcohol consumption among students when they proceed through their different academic years may be explored.

\section{Conclusion}

At our Institute, alcohol use by students is not alarming. Moreover, students did not allow their alcohol use to interfere with their academic performance. Majority of students did not miss any important academic events as a result of their alcohol consumption. In addition, alcohol consumption is not associated with other substance abuse. However, smoking may cooccur with alcohol use. Students consider alcohol intake as one of the method to deal with stress. The drinking habit which was developed during school time is more likely to continue during college years. Moreover, those who have non-drinking friends are more likely not to consume alcohol themselves. Family members 
and friends who consume alcohol may act as predisposing factor for alcohol consumption. Hence there is a need to educate students as well as parents regarding the health and social hazards of alcohol consumption.

\section{Reference}

1. Windle M. Alcohol use among adolescents and young adults. National institute on alcohol abuse and alcoholism. [2003 Dec]. Accessed on Feb 06, 2013. Available from: http://pubs.niaaa.nih.gov/publications/arh271/79-86.htm

2. Thombs DL, Olds RS, Bondy SJ, Winchell J, Baliunas D, Rehm J. Undergraduate Drinking and Academic Performance: A Prospective Investigation With Objective Measures. J Stud Alcohol Drugs 70: 776-785, 2009

3. Ganaraja B, Kotian MS, Ramesh MB, Ramaswamy C. Alcohol expectancy responses from first year medical students: Are they prone to alcoholism? Indian Journal of Medical Sciences. 2007: 61; 511-516

4. Flaherty JA, Richman JA. Substance Use and Addiction among Medical Students, Residents, and Physicians. Psychiatric Clin North Am. 1993;16(1):189-197.

5. Yousafzai AW, Ahmer S, Syed E, Bhutto N, Iqbal S, Siddiqi $\mathrm{MN}$ et al. Well-being of medical students and their awareness on substance misuse: a cross-sectional survey in Pakistan. Annals of General Psychiatry 2009, 8:8. Available from: http://www.annalsgeneral-psychiatry.com/content/8/1/8

6. Rahman AH, Zulkifli NAM, Kulanthayan KCM, Hua LT, Jailani F. Health risk behaviours and alcohol drinking among twenty year students in Selangor, Malaysia. The International Medical Journal Available from: http://www.eimjm.com/Vol3-No1/Vol3-No1B4.html

7. Shafiq M, Shah Z, Saleem A, Siddiqi TM, Shaikh KS, Salahuddin FF. Perceptions of Pakistani medical students about drugs and alcohol: a questionnaire-based survey. Substance Abuse Treatment, Prevention, and Policy 2006, 1:31. Available from: http://www.substanceabusepolicy.com/content/ $1 / 1 / 31$

8. Sherina MS, Rampal L, Kaneson N. Psychological Stress among Undergraduate
Medical Students. Med J Malaysia 2004;59:207-11.

9. Mosley TH Jr, Perrin SG, Neral SM, et al. Stress, coping and well-being among third year medical students. Acad Med 1994; 69: 765-7.

10. Wolf TM, Kissling GE. Changes in life-style characteristics, health and mood of freshman medical students. J Med Edu 1984; 59: 806-14.

11. Ko SM, Kua EH, Fones CSL. Stress and the Undergraduates. Singapore Med J 1999; 40: 627-30.

12. Yusoff MSB, Rahim AFA, Yaacob MJ. Prevalence and Sources of Stress among Universiti Sains Malaysia Medical Students. Malaysian J Med Sci. 2010; 17: 30-37.

13. Newbury-Birch D, White M, Kamali F. Factors Influencing Alcohol and Illicit Drug Use amongst Medical Students. Drug Alcohol Depend. 2000;59:125-130.

14. Pickard M, Bates L, Dorian M, Greig H, Saint D. Alcohol and Drug Use in Second-year Medical Students at the University of Leeds. Med Educ. 2000;34(2):148-150.

15. Johnson CC, Myers L, Webber LS, Hunter SM, Srinavasan SR, Berenson GS. Alcohol consumption among adolescent and young adults: the Bogalusa Heart Study,1981 to 1991. Am J of Public Health, 1995; 85:979-982.

16. Ritchey P, Reid G, Hasse L. The relative influence of smoking on drinking and drinking among high school students in a rural tobaccogrowing county. $\mathrm{J}$ of Adoles Health 2001;29:386-394.

17. Guthrie EA, Black D, Shaw CM, Hamilton J, Creed FH, Tomenson B. Embarking upon a medical career: Psychological morbidity in first year medical students. Med Educ. 1995;29:337-341.

18. Ashton CH, Kamali F. Personality, lifestyles, alcohol and drug consumption in a sample of British medical students. Med Educ. 1995;29(3):187-92.

19. Rozi S, Butt ZA, Akhtar S: Correlates of cigarette smoking among male college students in Karachi, Pakistan. BMC Public Health 2007;7:312. 